\title{
Piper novae-hollandiae Miq. Leaf Extracts Lack Antibacterial Activity and are Non-toxic in vitro
}

Lindiwe Mpala' ${ }^{1}$, Getmore Chikowe ${ }^{1}$, Ian Edwin Cock ${ }^{1,2, *}$

'School of Environment and Science, Nathan Campus, Griffith University, 170 Kessels Rd, Nathan, Brisbane, Queensland, AUSTRALIA.

2Environmental Futures Research Institute, Griffith University, 170 Kessels Rd, Nathan, Brisbane, Queensland, AUSTRALIA.

\begin{abstract}
Introduction: Closely related plant species often share similar secondary metabolites and bioactivities and are therefore good targets for bioactivity testing when one or more species within a genus are known to possess therapeutic properties. The genus Piper has a long history of medicinal usage in many areas of the world. Many Piper spp. are known to have therapeutic properties and several have antibacterial bioactivities. Methods: The ability of $P$. novae-hollandiae leaf extracts to inhibit the growth of a panel of bacterial pathogens was investigated by disc diffusion assay. Toxicity was examined using the Artemia franciscana nauplii bioassay. Results: P. novae-hollandiae methanolic and aqueous extracts were completely ineffective at inhibiting the growth of panels of gram-positive and gram-negative bacteria. The extracts were nontoxic or of low toxicity to Artemia nauplii following $24 \mathrm{~h}$ exposure. Conclusion: Despite the close taxonomic relationship with several bioactive Piper spp. and its therapeutic
\end{abstract}

use by first Australians, P. novae-hollandiae leaf extracts were completely ineffective bacterial growth inhibitors. However, these extracts may have other therapeutic properties and testing against protozoa, fungi, virus and tumour cells is warranted.

Key words: Piperaceae, Giant pepper vine, Australian plant, Traditional medicine, Medicinal plants, Toxicity.

\section{Correspondence:}

Dr. Ian Edwin Cock

School of Environment and Science, Nathan Campus, Environmental Futures Research Institute Griffith University, 170 Kessels Rd, Nathan, Brisbane, Queensland, AUSTRALIA.

Phone no: : +61 737357637

E-mail: I.Cock@griffith.edu.au

DOI: $10.5530 /$ pc.2019.2.14

\section{INTRODUCTION}

The use of natural plant therapeutics is as old as human civilisation and in many regions of the world is still the primary modality of health care. Ayuverdic medicine in India for example is still commonly practiced, with approximately $85 \%$ of Indians using crude plant preparations for the treatment of various diseases and ailments. ${ }^{1}$ Even in Western civilisations, plants play an important role in medicine. At least $25 \%$ of pharmaceuticals prescribed worldwide are directly obtained from plants and many more drugs are semi-synthetic derivatives of natural product precursors. ${ }^{2-4}$ Examples of medicinally important plant derived compounds include the anti-malarial drugs quinine (from Cinchona spp.) and artemesinin (from Artemisia annua L.) and their derivatives; the anti-tumour drugs vincristine and vinblastine (from Catharanthus roseus (L.) G. Don), along with the semi-synthetic analogue vindesine; the analgesics morphine and codeine (from Papaver somniferum L.); the anticholinogenic drug atropine derived from plants of the family Solinaceae (Atropa belladonna L., Datura stramonium L. and Mandragora officinarum L.); the anticancer drug taxol (derived from Taxus brevifolia Nutt.); and the cardiac glycoside digoxin (from Digitalis purpurea L.). ${ }^{5}$

Despite the potential of plants to provide us with useful pharmaceutical agents, the field is still relatively poorly studied. Only an estimated 5-10 $\%$ of the approximately $300,000-500,000$ plant species worldwide have been screened for 1 or more bioactivities. ${ }^{5}$ With so many plant species yet to be tested, it is essential that plant selection processes narrow the field. The main selection criteria currently used is to select plants on the basis of ethnobotanical usage as traditional medicines. Another important selection method is to examine plants closely related to species for which medicinal potential is well established. Many plant secondary metabolites are regarded as family, genus or species specific and investigation of species closely related to those used as traditional medicines may lead to natural therapeutic discovery of novel pharmaceuticals. ${ }^{2}$

In recent years, the development of either extremely (XDR) or totally drug resistant (TDR) bacterial pathogens ${ }^{6}$ has resulted in the need to develop new antibiotic chemotherapies. There are now limited therapeutic options for many diseases caused by bacteria and the situation is expected to worsen in the future as bacteria exchange resistance genes. Indeed, the development of alternative antibacterial treatment modalities has become crucial and is considered by the World Health Organisation (WHO) to be one of the most serious challenges currently facing medical science. ${ }^{7}$ For a number of reasons reviewed elsewhere ${ }^{6}$ it is unlikely that the previous methods of antibiotic discovery/development will be as successful in the future and new treatment modalities are urgently required. Traditional medicines and herbal remedies have great potential for antimicrobial drug development and there has recently been a substantial increase in interest in this field. ${ }^{8,9}$ The genus Piper (Family Piperaceae) consists of approximately 1000 species, many with global distribution..$^{10}$ Many Piper spp. are used as spices for their pleasant flavour characteristics, with Piper nigrum L. (black pepper) being the best known for this purpose. The raw unripe $P$. nigrum fruit yields green pepper, the unripe cooked fruit gives black pepper, whilst the ripe fruit is used as white pepper. Several Piper spp. also have long histories of medicinal use in the treatment of a wide variety of medical disorders and conditions. The genus Piper may be particularly useful as antibacterial therapies. Indeed, the use of Piper spp. extracts in ancient Asian ethnopharmacological practices has been well documented and $P$. nigrum is a component of many traditional medicines still commonly in use. ${ }^{10}$ Piper guineense Schumach. has similar therapeutic uses. Substantially less information is known about the Australian species Piper novae-hollandiae Miq., although its medicinal uses by the first Australians have been recorded. ${ }^{11,12}$ Whilst it is mainly known for its tonic properties, it was also used in the treatment of some bacterial diseases, including STIs. ${ }^{11}$

P. novae-hollandiae (commonly known as giant pepper vine) is a vigorous climbing vine that grows attached to trees (Figure 1a) in rainforest regions in eastern Australia. P. novae-hollandiae has glossy green ovate leaves (up to $12 \mathrm{~cm}$ by $9 \mathrm{~cm}$ ) (Figure $1 \mathrm{~b}$ ). Small cream coloured flowers form in April to August and develop into small oval shaped red drupes 
(Figure 1c). There is a lack of information on the phytochemical composition of this species. However, the phytochemistry of other species has been reported ${ }^{13}$ and is characterised by relatively high levels of mono- and sesquiterpenoids, including piperitone, (Figure 1d), myrcene (Figure 1e), a-pinene (Figure 1f), caryophyllene (Figure 1g), caryophyllene oxide (Figure 1h), $\beta$-selinene (Figure 1i) and viridiflorol (Figure 1j). Many of these have been reported to have potent antibacterial activity ${ }^{14}$ and may therefore contribute to the antibacterial properties of other Piper spp. This study was undertaken to screen of $P$. novae-hollandiae leaf extracts for the ability to inhibit the growth of a panel of gram-positive and gram-negative bacterial pathogens.

\section{MATERIALS AND METHODS}

\section{Collection of Plant Material and Extraction}

Piper novae-hollandiae Miq. Leaves were harvested from wild plants in Toohey Forest Australia, washed in deionised water and processed within $4 \mathrm{hrs}$ of collection. The leaves were dried in a Sunbeam food dehydrator and the dried material was ground to a coarse powder. Individual $1 \mathrm{~g}$ masses of the dried plant material was extracted extensively in $50 \mathrm{~mL}$ methanol (Ajax, AR grade) or deionised water for $24 \mathrm{hrs}$ at $4^{\circ} \mathrm{C}$ with gentle shaking. The extract was filtered through filter paper (Whatman No. 54) under vacuum followed by drying by rotary evaporation. The resultant pellet was dissolved in $5 \mathrm{~mL}$ deionised water. The extract was passed through $0.22 \mu \mathrm{m}$ filter (Sarstedt) and stored at $4^{\circ} \mathrm{C}$.

\section{Qualitative Phytochemical Studies}

Phytochemical analysis of the P. novae-hollandiae leaf extracts for the presence of saponins, phenolic compounds, flavonoids, phytosteroids, triterpenoids, cardiac glycosides, anthraquinones, tannins and alkaloids was conducted by standard assays. ${ }^{15-17}$

\section{Antibacterial Screening}

\section{Test Microorganisms}

All media was purchased from Oxoid Ltd., Australia. The reference strains of E. coli (ATCC157293), Klebsiella pneumoniae (ATCC31488), Proteus mirabilis (ATCC21721) and Streptococcus pyogenes (ATCC19615) were purchased from American Tissue Culture Collection (ATCC), USA. Clinical isolate microbial strains of Aeromonas hydrophilia, Alcaligenes feacalis, Bacillus cereus, Citrobacter freundii, Pseudomonas fluorescens, Salmonella newport, Serratia marcescens, Shigella sonneii, Staphylococcus aureus and Staphylococcus epidermidis strains were obtained from Ms Michelle Mendell and Ms Jane Gifkins, Griffith University. All stock cultures were subcultured and maintained in nutrient broth at $4^{\circ} \mathrm{C}$.

\section{Evaluation of Antimicrobial Activity}

Antimicrobial activity of the P. novae-hollandiae leaf extracts was determined using a modified disc diffusion assay. ${ }^{18-20}$ Briefly, $100 \mu \mathrm{L}$ of the each bacterial suspension in log phase was spread onto individual nutrient agar plates and the extracts were tested for antibacterial activity using $6 \mathrm{~mm}$ sterilised filter paper discs. The discs were each infused with $10 \mu \mathrm{L}$ of the individual plant extract, allowed to dry and placed onto the inoculated plates. The plates were allowed to stand at $4^{\circ} \mathrm{C}$ for $2 \mathrm{~h}$ before incubation at $37^{\circ} \mathrm{C}$ for $24 \mathrm{~h}$. The diameters of the zones of inhibition (ZOIs) were measured to the closest whole millimetre. Each assay was performed three times in triplicate $(n=9)$. Mean values $( \pm$ SEM) are reported in this study. Standard discs of ampicillin $(10 \mu \mathrm{g})$ and chloramphenicol $(10 \mu \mathrm{g})$ were obtained from Oxoid, Australia and were used as positive controls to compare antibacterial activity. Filter discs infused with $10 \mu \mathrm{L}$ of distilled water were used as a negative control.

\section{Artemia franciscana Nauplii Toxicity Screening}

Toxicity was tested using an adapted Artemia franciscana nauplii lethality assay. ${ }^{21-23}$ Briefly, A. franciscana nauplii were incubated in the presence of the extracts, reference toxin $(1 \mathrm{mg} / \mathrm{mL}$ potassium dichromate) or artificial seawater (negative control) at $25 \pm 1^{\circ} \mathrm{C}$ under artificial light. All treatments were performed three times in triplicate $(n=9)$. The number of dead were counted in each well at $24 \mathrm{~h}$ and $48 \mathrm{~h}$. At the completion of the $48 \mathrm{~h}$ exposure period, the remaining live nauplii were sacrificed and the total number of nauplii in each well were counted and used to calculate the $\%$ mortality per well. LC $_{50}$ values were calculated for each treatment using probit analysis.

\section{Statistical Analysis}

Data are expressed as the mean \pm SEM of three independent experiments with internal triplicates $(n=9)$. One-way ANOVA was used to calculate statistical significance between control and treated groups, with a $P$ value $<0.01$ considered to be statistically significant.

\section{RESULTS}

\section{Liquid Extraction Yields and Qualitative Phytochemical Screening}

Extraction of $1 \mathrm{~g}$ of dried and powdered $P$. novae-hollandiae leaves with methanol and water yielded 296 and $265 \mathrm{mg}$ of extracted material respectively (Table 1). The extracts were resuspended in $10 \mathrm{~mL}$ of deionised water (containing 1\% DMSO), resulting in an extract concentration shown in Table 1. Qualitative phytochemical studies showed that both extracts had similar phytochemical profiles. Both contained high levels of phenolic compounds and flavonoids. Lower levels of saponins, triterpenoids and tannins were also detected. Cardiac glycosides, phytosterols, alkaloids and anthraquinones were completely absent or below the detection thresholds for these assays.

\section{Antibacterial Activity}

To determine the growth inhibitory activity of the P. novae-hollandiae leaf extracts, aliquots $(10 \mu \mathrm{L})$ of each extract were screened in the disc diffusion assay. The $P$. novae-hollandiae leaf extracts were ineffective at inhibiting the growth of all gram-negative (Figure 2) and gram-positive (Figure 3) bacterial species tested. In contrast, both positive control antibiotics (ampicillin and chloramphenicol) were effective growth inhibitors, with ZOI's of up to $14.3 \mathrm{~mm}$ (chloramphenicol against $E$. coli). We were therefore unable to determine MIC values for the extracts against any bacteria as they were completely ineffective at all concentrations tested.

\section{Quantification of Toxicity}

The toxicity of the P. novae-hollandiae leaf extracts was initially tested at $2 \mathrm{mg} / \mathrm{mL}$ in the $A$. franciscana nauplii bioassay (Figure 4 ). The mortality in the presence of all extracts was not significantly different to that of the untreated control at $24 \mathrm{~h}$ and thus were deemed to be non-toxic. Extracts with $24 \mathrm{~h} \mathrm{LC}_{50}$ values $>1000 \mu \mathrm{g} / \mathrm{mL}$ have previously been defined as non-toxic. ${ }^{23}$ In contrast, the potassium dichromate positive control induced substantial mortality within 4 h (results not shown), with $100 \%$ mortality induction seen by $24 \mathrm{~h}$. The mortality increased following exposure to the $P$. novae-hollandiae leaf extracts at $48 \mathrm{~h}$ and was further increased following $72 \mathrm{~h}$ exposure.

\section{DISCUSSION}

Due to recent increases in bacterial resistance to many antibiotics, the development of new antibiotic chemotherapies is a high priority for medical science. ${ }^{6,7}$ A concurrent decrease in the discovery of new 
Table 1: The Mass of Dried Extracted Material, the Concentration After Resuspension in Deionised Water and Qualitative Phytochemical Screenings of the P. novae-hollandiae Leaf Extracts.

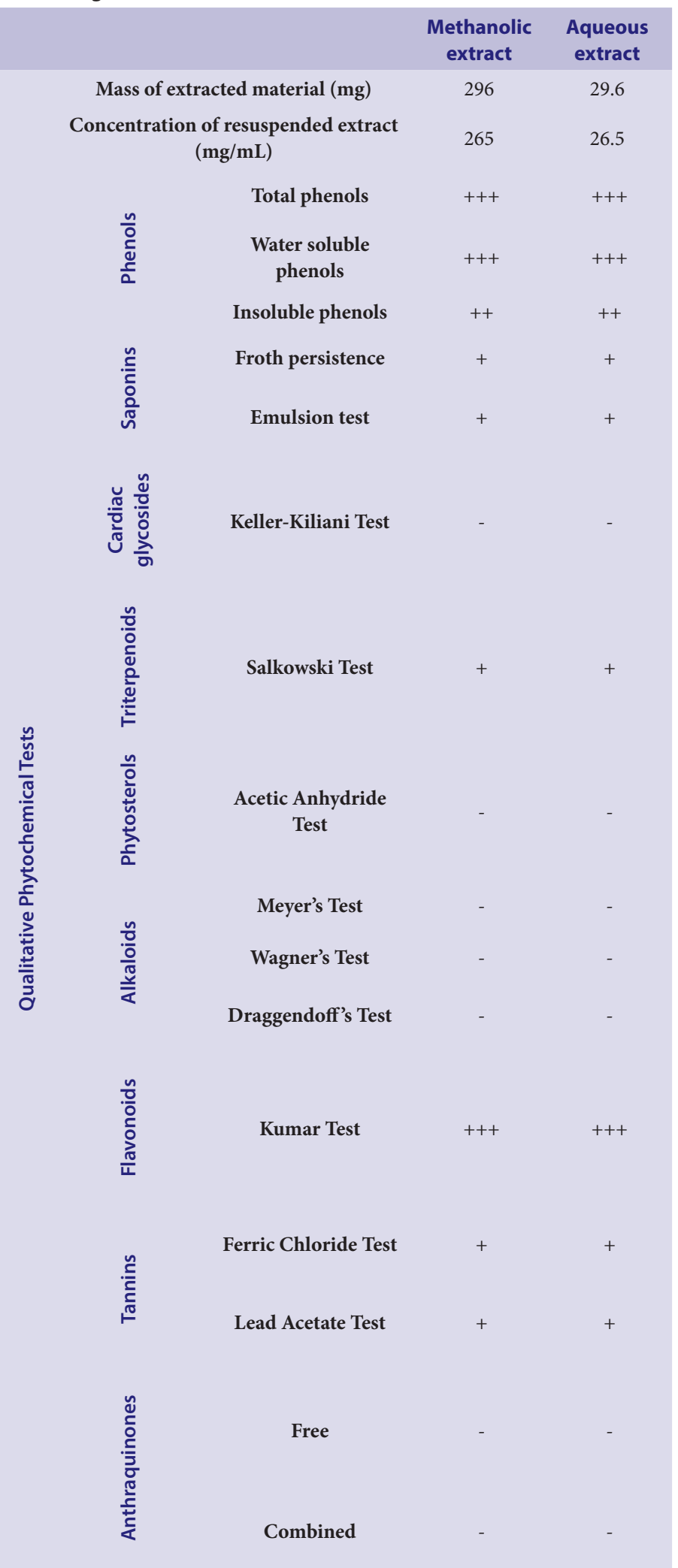

+++ indicates a large response; ++ indicates a moderate response; + indicates a minor response; - indicates no response in the assay.
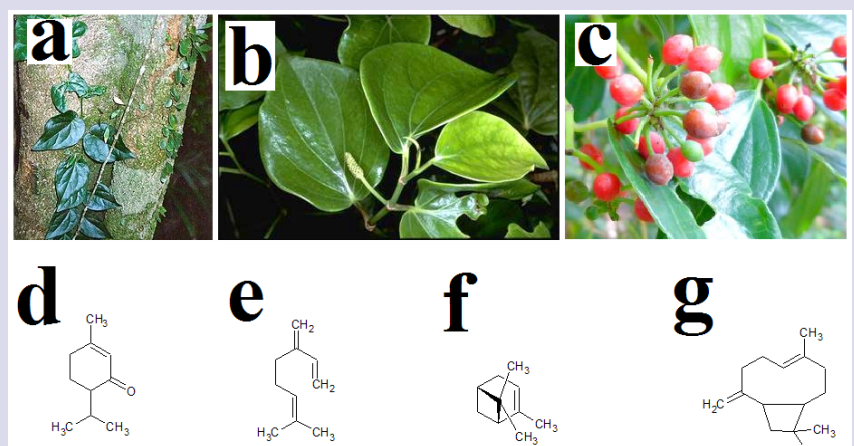<smiles>CC(C)CC(C)C</smiles><smiles>CC(C)C1(C)C2CCC1C2(C)C</smiles>
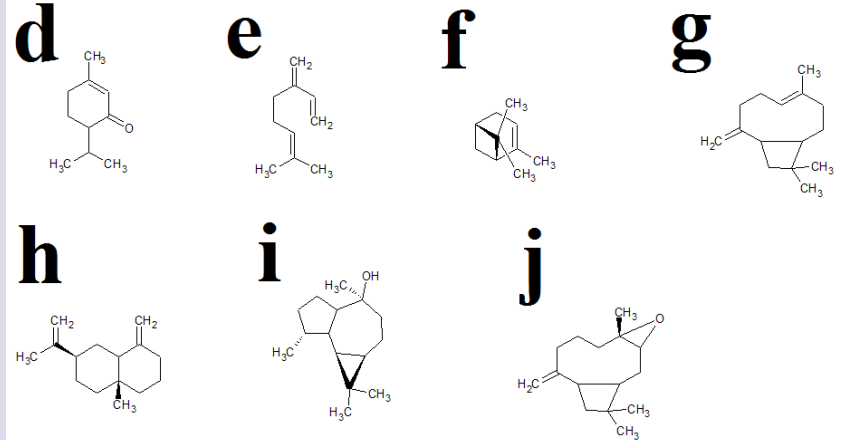

Figure 1: P. novae-hollandiae (a) plant attached to a tree, (b) leaves, (c) fruit and the structures of common terpenoids in other Piper spp.: (d) piperitone, (e) myrcene, (f) a-pinene, (g) caryophyllene, ( $h$ ) caryophyllene oxide, (i) $\beta$-selinene and ( $j$ ) viridiflorol.

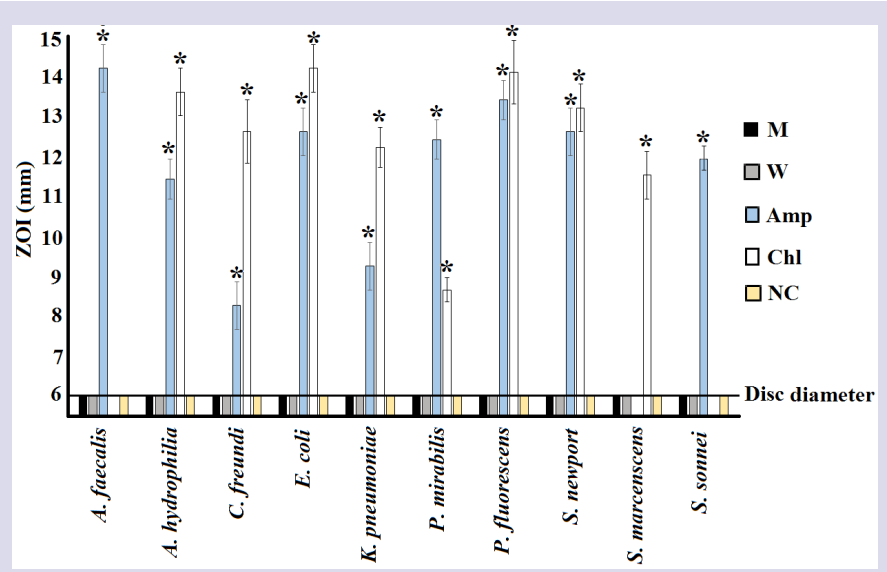

Figure 2: Growth Inhibitory activity of $P$. novae-hollandiae leaf extracts and reference antibiotics against gram-negative bacterial species measured as ZOls $(\mathrm{mm}) \pm$ SEM. Ampicillin (Amp) and chloramphenicol (Chl) standard discs $(10 \mu \mathrm{g})$ were used as positive controls. $\mathrm{M}=$ methanolic extract; $\mathrm{W}=$ aqueous extract; $\mathrm{NC}=$ negative control. All assays were completed three times, each with internal triplicates $(n=9)$ and the results are expressed as mean zones of inhibition $(\mathrm{mm}) \pm \mathrm{SEM} .{ }^{*}$ indicates results that are significantly different to the untreated control $(P<0.01)$.

antibiotic medicines by conventional strategies has increased interest in re-evaluating medicinal plants for new antibiotic chemotherapies. ${ }^{24}$ P. novae-hollandiae was used by the first Australians to treat a number of diseases, some of which are caused by bacterial pathogens. Furthermore, as $P$. novae-hollandiae is taxonomically related to other species including $P$. nigrum and $P$. guineense that have antibacterial activity, it was deemed a viable target for antibacterial screening. Surprisingly, the $P$. novaehollandiae extracts were completely inactive against all gram-positive and gram-negative bacteria tested.

It is noteworthy that a single assay technique was used to screen for antibacterial activity in this study. We chose to use the disc diffusion assay as it is a rapid methodology and it has previously been widely utilised 


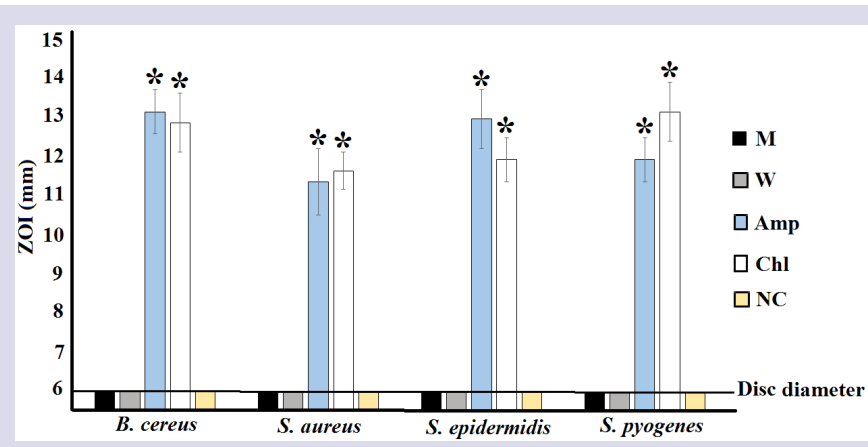

Figure 3: Growth inhibitory activity of $P$. novae-hollandiae leaf extracts and reference antibiotics against gram-positive bacterial species measured as ZOls $(\mathrm{mm}) \pm$ SEM. Ampicillin (Amp) and chloramphenicol (Chl) standard discs $(10 \mu \mathrm{g})$ were used as positive controls. $\mathrm{M}=$ methanolic extract; $\mathrm{W}=$ aqueous extract; $\mathrm{NC}=$ negative control. All assays were completed three times, each with internal triplicates $(n=9)$ and the results are expressed as mean zones of inhibition $(\mathrm{mm}) \pm \mathrm{SEM}$. ${ }^{*}$ indicates results that are significantly different to the untreated control $(P<0.01)$.

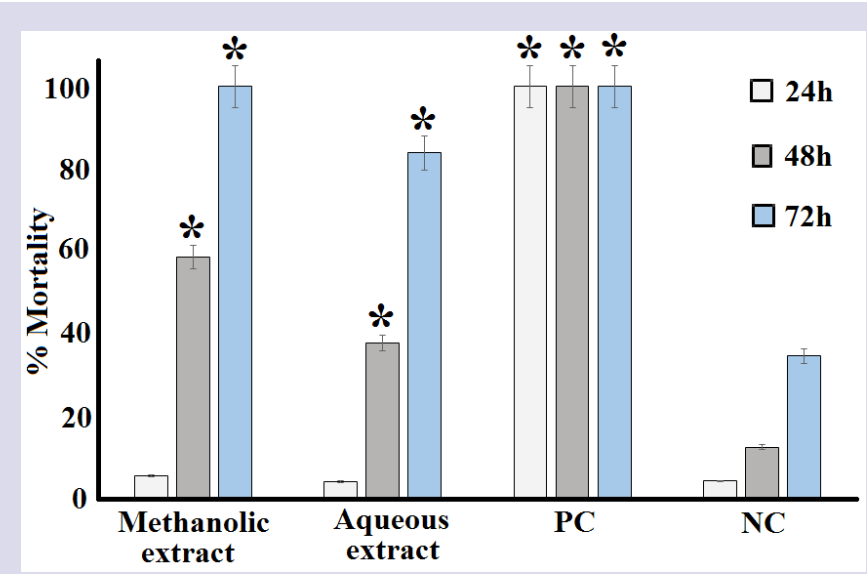

Figure 4: The lethality of the $P$. novae-hollandiae leaf extracts, potassium dichromate control $(1000 \mu \mathrm{g} / \mathrm{mL})$ and seawater (negative control) following 24,48 and 72 hrs of exposaure. All bioassays were performed three times in triplicate $(n=9)$ and are expressed as mean \pm SEM. ${ }^{*}$ indicates results that are significantly different to the untreated (seawater) control at the equivalent exposure time $(P<0.01)$

in other studies. Therefore, comparisons between studies are relatively simple. However, as the disc diffusion method is reliant on the diffusion of a molecule through the aqueous environment of an agar gel, this assay may be affected by the solubility of the extract compounds in the aqueous environment. Polar compounds that are highly soluble in water would be expected to diffuse easily in the gel, whereas less soluble compounds would not diffuse as readily and thus be concentrated around the disc. For this reason, whilst this is a handy assay for screening aqueous extracts, this technique may not be ideal for nonpolar compounds (e.g. when screening essential oil and their components). For examining nonpolar mixtures, other techniques such as liquid dilution assays may be preferred. As Piper spp. are known to contain relatively high levels of nonpolar terpenoid components, their activity may have been significantly under estimated in our study. Liquid dilution studies may have been better suited to screen the $P$. novae-hollandiae for activity and future studies will use these techniques to re-examine the extracts for antibacterial activity.

Diffusion of molecules within an agar gel is also affected by the size of the molecules. The movement of large, complex phytochemicals (e.g. complex tannins) through agar gels by diffusion would also be hampered and may provide a false idea of the efficacy of an extract. As many tannins have well described antibiotic properties, screening for growth inhibition using agar diffusion techniques may have given a distorted view of the inhibitory potential of the extracts.

The findings reported here also indicate that the extracts examined were non-toxic $\left(24 \mathrm{~h} \mathrm{LC}_{50}>1000 \mu \mathrm{g} / \mathrm{mL}\right)$ in the Artemia nauplii bioassay. Whilst toxicity was assessed in this study with the test organism $A$. franciscana, toxicity towards $A$. franciscana has previously been shown to correlate well with toxicity towards human cells for many toxins. ${ }^{23}$ However, further studies are required to determine whether this is also true for the P. novae-hollandiae leaf extracts examined in these studies.

\section{CONCLUSION}

Methanolic and aqueous $P$. novae-hollandiae leaf extracts displayed no antibacterial activity in the disc diffusion assay against a panel of human pathogenic bacteria, despite their close taxonomic relationship with other Piper spp. with well known antibacterial properties. The extracts were nontoxic towards Artemia nauplii.

\section{ACKNOWLEDGEMENT}

The authors are grateful to Michelle Mendell and Jane Gifkins of Griffith University for providing the clinical bacterial strains used in this study. Financial support for this work was provided by the Environmental Futures Research Institute and the School of Natural Sciences, Griffith University, Australia.

\section{CONFLICT OF INTEREST}

The authors declare no conflict of interest.

\section{ABBREVIATIONS}

DMSO: Dimethyl sulfoxide; $\mathbf{L C}_{50}$ : The concentration required to achieve 50 \% mortality; MIC: Minimum inhibitory concentration; ZOI: Zone of inhibition.

\section{REFERENCES}

1. Kamboj VP. Herbal medicine. Curr Sci. 2000;78(1):35-9.

2. Hostettmann K, Hamburger M. Search for new lead compounds of natural origin. In Perspectives in Medical Chemistry. Verlag Helvitica Acta Basel. 1993.

3. Newman DJ, Cragg GM, Snader KM. The influence of natural products on drug discovery. Nat Prod Rep. 2000;17(3):215-34.

4. Walsh G. Biopharmaceuticals: Biochemistry and Biotechnology. $3^{\text {rd }}$ ed. Wiley, Chinchester. 2003.

5. Gilani AH, Atta-ur-Rahman. Trends in ethnopharmacology. J Ethnopharmacol. 2005; 100(1-2):43-9.

6. Cheesman MJ, Ilanko A, Blonk B, Cock IE. Developing new antimicrobial therapies: Are synergistic combinations of plant extracts/compounds with conventional antibiotics the solution?. Pharmacog Rev. 2017;11(22):57-72. DOI: 10.4103/phrev.phrev_21_17

7. WHO. Antimicrobial Resistance. World Health Organization. 2016. Available from: http://www.who.int/mediacentre/factsheets/fs194/en/. [Cited on 2017 May 10].

8. Sirdaarta J, Matthews B, Cock IE. Kakadu plum fruit extracts inhibit the growth of the bacterial triggers of rheumatoid arthritis: Identification of stilbene and tannin components. J Funct Food. 2015;17:610-20. DOI: 10.1016/j.jff.2015.06.019

9. Ilanko A, Cock IE. The interactive antimicrobial activity of contentional antibiotics and Petalostigma spp. Extracts against bacterial triggers of some autoimmune inflammatory diseases. Pharmacog J. 2019;11(2): 292-309. DOI: 10.5530/ pj.2019.11.45.

10. Scott IM, Jensen HR, Philogène BJ, Arnason JT. A review of Piper spp (Piperaceae) phytochemistry, insecticidal activity and mode of action. Phytochem Rev. 2008;7(1):65-75. 
11. Lassak EV, McCarthy T. Australian Medicinal Plants. New Holland Publishers Sydney Australia. 2011

12. Cock IE. Medicinal and aromatic plants - Australia. In Ethnopharmacology, Encyclopedia of Life Support Systems (EOLSS). Developed under the auspices of UNESCO. Oxford, UK: EOLSS Publishers. 2011. Available from: http://www. eolss.net.

13. DeMorais SM, Facundo VA, Bertini LM, et al. Chemical composition and larvicidal activity of essential oils from Piper species. Biochem Syst Ecol. 2007;35(10):670-5

14. Cock IE. The phytochemistry and chemotherapeutic potential of Tasmannia lanceolata (Tasmanian pepper): A review. Pharmacog Commn. 2013;3(4):13-25. DOI: $10.5530 /$ pc.2013.4.3

15. Hart C, llanko P Sirdaarta J et al. Tasmannia stipitata as a functional food/ natural preservative: Antimicrobial ctivity and toxicity. Pharmacog Commn 2014;4(4):33-47. DOI: 10.5530/pc.2014.4.4

16. Winnett $\mathrm{V}$, Sirdaarta J, White A, et al. Inhibition of Klebsiella pneumonia growth by selected Australian plants: Natural approaches for the prevention and management of ankylosing spondylitis. Inflammopharmacol. 2017;25(2):22335. DOI: 10.1007/s10787-017-0328-1

17. Wright $\mathrm{MH}$, Matthews $\mathrm{B}$, Arnold MSJ, et al. The prevention of fish spoilage by high antioxidant Australian culinary plants: Shewanella putrefaciens growth inhibition. Int J Food Sci Technol. 2016;51(3):801-13. DOI: 10.1111/ijfs.13026

18. Mpala L, Chikowe G, Cock IE. No evidence of antiseptic properties and low toxicity of selected Aloe species. J Pharm Negative Results. 2010;1(1):10-6 DOI: 10.4103/0976-9234.68869

19. Lee CJ, Wright MH, Arnold MSJ, et al. Inhibition of Streptococcus pyogenes growth by native Australian plants: New approaches towards the management of impetigo, pharyngitis and rheumatic heart disease. Pharmacog Commn. 2016;6(3):164-73. DOI: 10.5530/pc.2016.3.6

20. Wright $\mathrm{MH}$, Arnold MSJ, Lee CJ, et al. Qualitative phytochemical analysis and antibacterial activity evaluation of Indian Terminalia spp. against the pharyngitis causing pathogen Streptococcus pyogenes. Pharmacog Commn. 2016;6(2):8592. DOI: $10.5530 /$ pc.2016.2.6

21. Cock IE, Winnett $V$, Sirdaarta J, et al. The potential of selected Australian medicinal plants with anti-Proteus activity for the treatment and prevention of rheumatoid arthritis. Pharmacog Mag. 2015;11(Suppl 1):S190-208. DOI: 10.4103/09731296. 157734

22. Hart C, Cock IE. An examination of the antimicrobial and anticancer properties of Garcinia cambogia fruit pericarp extracts. BEMS Reports. 2016:2(1):23-6. DOI: 10.5530/BEMS.2016.2.10

23. Cock IE Ruebhart DR. Comparison of the brine shrimp nauplii bioassay and the ToxScreen-II test for the detection of toxicity associated with Aloe vera (Aloe barbadensis Miller) leaf extract. Pharmacog Res. 2009;1(2):98-101.

24. Aiyegoro OA, Okoh Al. Use of bioactive plant products in combination with standard antibiotics: Implications in antimicrobial chemotherapy. Journal of $\mathrm{Me}$ dicinal Plants Research. 2009:3(13):1147-52

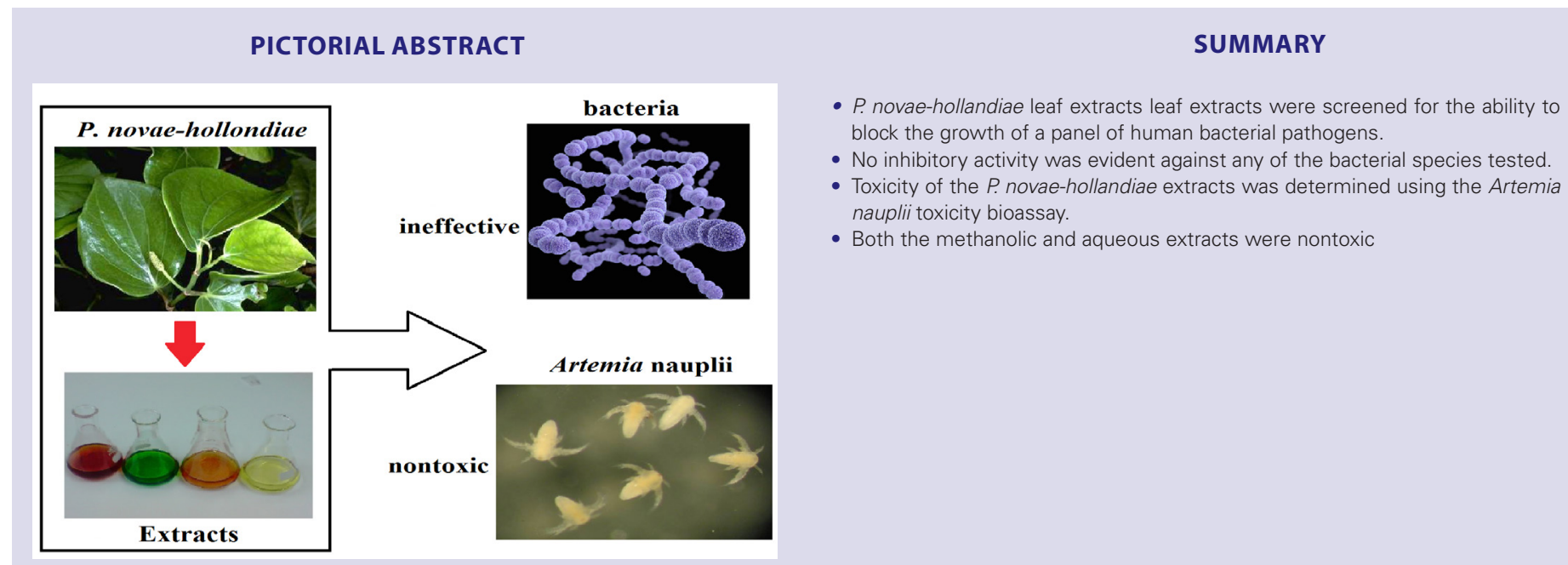

ABOUT AUTHORS

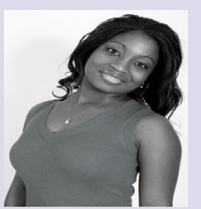

Getmore Rumbudzai Chikowe: Ms Getmore Chikowe completed BSc at Griffith University in life sciences. Following graduation, she undertook a research project in Dr lan Cock's laboratory in the School of Natural Sciences at Griffith University. The project examined the growth inhibitory properties of a variety of Australian native plants against an extensive panel of bacterial pathogens.

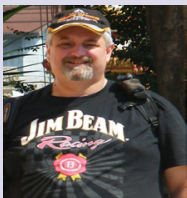

Dr lan Cock leads a research team in the Environmental Futures Research Institute and the School of Natural Sciences at Griffith University, Australia. His research involves bioactivity and phytochemical studies into a variety of plant species of both Australian and international origin, including Aloe vera, South Asian and South American tropical fruits, as well as Australia plants including Scaevola spinescens, Pittosporum phylliraeoides, Terminalia ferdinandiana (Kakadu plum), Australian Acacias, Syzygiums, Petalostigmas and Xanthorrhoea johnsonii (grass trees). This range of projects has resulted in nearly 200 publications in a variety of peer reviewed journals.

Lindiwe Nomathemba Mpala: Ms Lindiwe Mpala completed BSc at Griffith University in life sciences. Following graduation, she undertook a research project in Dr lan Cock's laboratory in the School of Natural Sciences at Griffith University. The project examined the growth inhibitory properties of a variety of Australian native plants against an extensive panel of bacterial pathogens. 